
\section{$E_{\text {citus }}$} Human Sciences, University of Manchester, Manchester, UK ${ }^{2}$ North West Lung Centre, University Hospital of South Manchester, Manchester, UK

\section{Correspondence to} Dr Heather Diane Green, North West Lung Centre, Wythenshawe Hospital, Southmoor Road, Manchester, M23 9LT, UK;

heatheryoung@doctors.net.uk

Received 20 May 2014 Revised 26 June 2014 Accepted 14 July 2014 Published Online First 25 July 2014

\title{
Central cyanosis on a psychiatric unit treated at the Salford Royal Hospital
}

\author{
Darren Green, ${ }^{1}$ Peter Barry, ${ }^{2}$ Heather D Green ${ }^{2}$
}

\section{ABSTRACT}

We describe a case of acquired methaemoglobinaemia due to frequent use of the 'legal high' known as 'Pink Panthers'. This contains 5,6-Methylenedioxy-2aminoindane and 2-Aminoindane, both amphetamine analogues with the potential to cause

methaemoglobinaemia. Furthermore, the most common 'cutting agent' for legal highs in the UK is benzocaine, also known to cause methaemoglobinaemia. Given the increasing prevalence of legal highs, particularly those containing added benzocaine, such presentations may become more common. Furthermore, in one case series, benzocaine gel used for toothache was the second most common reason for hospitalisation due to acquired methaemoglobinaemia after dapsone use. Indeed, the Federal Drug Agency has issued as public warning as to the risk of these products. We therefore think that clinicians and the public should be made more aware of the risk associated with such agents.

\section{CASE REPORT}

Darren Green (DG): A patient was transferred to the emergency department from an in-patient psychiatric unit after complaining to nursing staff of 5 min of sudden onset dizziness, and feeling nonspecifically unwell. During my evaluation, the patient was generally only able to answer direct questions due to treatment refractory schizophrenia for which they were prescribed mirtazapine, orphenadrine, sodium valproate and levomepromazine. The patient had been given oral amoxicillin by a general practitioner for shortness of breath and green sputum 4 weeks ago, but this had quickly resolved. There were no such symptoms at present on review of systems. The smoking history was of 20 cigarettes per day since the age of 15 , but this has doubled to 40 cigarettes per day since admission to the psychiatric unit 2 weeks ago. Observations were: $\mathrm{spO}_{2} 90 \%$ on $10 \mathrm{~L} / \mathrm{min} \mathrm{O}_{2}$ via a non-rebreathe mask, respiratory rate 22 per minute, blood pressure $135 / 87 \mathrm{~mm} \mathrm{Hg}$, heart rate 76 beats per minute, temperature $37.1^{\circ} \mathrm{C}$. Clinical examination was normal but for central cyanosis, and a plain AP chest radiograph was unremarkable.

Heather Green (HG): Sudden onset hypoxia in an apparently physically well patient is uncommon. The most frequent diagnosis is pulmonary embolus, but few patients will present with dizziness as their only symptom. Furthermore, dizziness is likely to be due to haemodynamic compromise, which is not present here. A radiograph has ruled out a significant pneumothorax or infection. Cyanosis and hypoxia may occur in congenital cardiac conditions that cause right to left shunt, but the speed of onset and absence of added heart sounds would, I agree, favour an acute respiratory diagnosis. Here, we urgently require an arterial blood gas to confirm hypoxia and to assess for methaemoglobinaemia (MetHb). If this were normal then, using Well's criteria, this patient would have a moderate clinical probability of pulmonary embolus. Prompt laboratory results for d-dimer would be helpful in this situation. If raised, an urgent CT pulmonary angiogram would be the next investigation of choice.

DG: An arterial blood gas sample taken on $10 \mathrm{~L} / \mathrm{min}$ of oxygen via a non-rebreathe mask showed $\mathrm{pO}_{2} 25.5 \mathrm{kPa}$ (reference range 10.5-13.5 $\mathrm{kPa}), \mathrm{pCO}_{2} 5.5 \mathrm{kPa}(4.5-6.0 \mathrm{kPa})$, oxyhaemoglobin $74.2 \%(96-100 \%)$ and MetHb 22.7\% (<1\%). The d-dimer was $44 \mathrm{ng} / \mathrm{mL}(<250 \mathrm{ng} / \mathrm{mL})$.

HG: This confirms MetHb as the cause of the cyanosis. MetHb is almost always an acquired condition if first presentation is in adulthood. Acquired $\mathrm{MetHb}$ is usually due to the oxidising effect of certain prescribed drugs or their metabolites on the ferrous iron $\left(\mathrm{Fe}^{2+}\right)$ of the haem group of haemoglobin. The oxidation process converts the $\mathrm{Fe}^{2+}$ ions to the ferric form $\left(\mathrm{Fe}^{3+}\right)$ which prevents the binding of oxygen. MetHb can be a rare side effect of many drugs, including over-the-counter therapies, such as benzocaine gel used for toothache and for teething in infants. Indeed, in one case series, benzocaine gel or spray was the second most common reason for acquired MetHb after dapsone ingestion. ${ }^{1}$ The Federal Drug Agency has gone as far as issuing a public warning as to the use of these products. ${ }^{2}$ Among potential culprit drugs is sodium valproate, which our patient is prescribed. We need to know if there has there been any change in dose of this drug, and a more detailed drug history must also be taken, as MetHb is a very rare side effect of valproate. We must also establish if there have been any other recent clinical observations taken on this patient. MetHb up to $15 \%$ can be asymptomatic in some cases, and it may be that this acute presentation hides a chronic side effect of antipsychotic therapy. With MetHb levels of 15$20 \%$ or more, patients develop cardiac and neurological symptoms as a result of hypoxia. Depending on comorbidities, these may be syncope or presyncope, headache, dyspnoea or confusion. Risk of death is usually present at levels $>50 \%$ and very likely at $>70 \%$.

Although this patient has had an acute increase in cigarette consumption, smoking alone does not lead to $\mathrm{MetHb}$ in this range, nor does timing of 
last cigarette relative to blood gas sampling significantly affect levels.

DG: Collateral history from the psychiatric unit staff indicates that there has been no change in valproate dose for 12 months. $\mathrm{SpO}_{2}$ on admission 2 weeks ago was 93\%, and this was presumed to be due to the recent respiratory tract infection and smoking history, and not investigated further. With hindsight, we can question whether arterial blood gas sampling in apparently hypoxic patients taking drugs that may cause MetHb should be a routine measure.

HG: Pulse oximetry is unreliable in the evaluation of MetHb. $\mathrm{SpO}_{2}$ can be within standard target range (94-98\%). In one experimental canine model, pulse oximetry $\mathrm{spO}_{2}$ was always $\geq 85 \%$ even in the presence of MetHb $>70 \%$. Conversely, cyanosis can appear with lower levels of MetHb ( $\geq 2 \mathrm{~g} / \mathrm{dL})$ compared to deoxygenated haemoglobin seen in cyanosis due to hypoxia $(\geq 5 \mathrm{~g} / \mathrm{dL}$ ). For these reasons, arterial blood gas monitoring must be used to accurately monitor cases of MetHb.

DG: I have also asked whether over-the-counter or illicit drugs are available to in-patients on this unit. Illegal agents are prohibited but patients commonly use 'legal highs'. On direct questioning, the patient confirmed the regular use of 'Pink Panthers' including 2 tablets prior to this acute episode.

HG: After careful collateral drug history, we have established that the most likely cause of this episode of MetHb is use of the 'legal high' known as Pink Panthers. Pink Panthers have previously been reported as the cause of a number of hospitalisations in the UK, but there is no previous report of these causing MetHb. The tablet is marketed as a combination of 5,6-Methylenedioxy-2-aminoindane (MDAI) and 2Aminoindane (2-AI). These are both amphetamine analogues, explaining their appeal as street drugs and the mechanism of MetHb. The association of illicit drugs with MetHb is well established. Methamphetamine ('crystal meth') and cocaine are the most widely available and widely acknowledged examples. However, many other drugs have the potential to cause MetHb. A chemical analysis of 22 other legal highs, along with their street names, has previously been published and may act as a useful reference point where MetHb due to drug use is suspected $^{3}$ (a list of agents previously reported to be associated with MetHb, prescribed or otherwise, is found in table 1). A significant confounding factor is that street drugs are often mixed with or replaced by 'cutting agents' which bulk out a product while lowering the unit cost. This means that the supposed contents of a drug may not be correct. ${ }^{4}$ For example, Pink Panthers have been shown to contain benzocaine, and this may be the actual cause of the MetHb in our case. Benzocaine is the most common cutting agent in the UK, but is less common elsewhere.

DG: This patient's MetHb quickly resolved without intervention, reaching $2.1 \%$ at $12 \mathrm{~h}$, negating the need for methylene blue, and supporting the working diagnosis of illicit drugs rather than valproate as the cause of the MetHb.
Table 1 Examples of agents known to cause acquired methaemoglobinaemia

\begin{tabular}{|c|c|c|}
\hline $\begin{array}{l}\text { Prescribed } \\
\text { medication }\end{array}$ & Illicit drugs & $\begin{array}{l}\text { Over-the-counter } \\
\text { products }\end{array}$ \\
\hline Dapsone & Methamphetamine ('crystal meth') & Benzocaine gel/spray \\
\hline Trimethoprim & Mephodrone ('snow'/'meow') & Fava beans \\
\hline Metoclopramide & Cocaine ('coke'/'blow'/'crack') & Inorganic nitrate fertilisel \\
\hline Sodium valproate & Amyl nitrate ('poppers') & \\
\hline Cloroquine & MDAI ('woof woof'/'pink panthers') & \\
\hline \multicolumn{3}{|l|}{ Zopiclone } \\
\hline \multicolumn{3}{|l|}{ Lidocaine } \\
\hline Methylene blue & & \\
\hline
\end{tabular}

HG: While this patient did not need methylene blue, its mention highlights a further important discussion point in management of MetHb caused by street drugs. Because these agents are unregulated, it can never be certain what chemicals have actually been consumed. Some cutting agents, such as phenylamine, as well as more common drugs such as cocaine, can cause rebound $\mathrm{MetHb}$ after methylene blue therapy, and so patients must be monitored for stability before discharge. ${ }^{5}$ Alternatively, failure to respond to therapy may indicate G6PD deficiency. This must not be ignored, as methylene blue can actually cause MetHb and also haemolysis in the presence of G6PD deficiency.

DG: To summarise, detailed drug history must be taken from patients presenting with MetHb. However, if street drugs are included in the history but do not appear to be associated with $\mathrm{MetHb}$, unlisted cutting agents, such as benzocaine, may be present that are the actual culprit. Unfortunately, such cases appear to be becoming more common and due diligence in detecting and managing these must be followed.

Contributors DG: Case discussion and first draft manuscript preparation. PB: Transcription of case discussion and expert view/editorial input. HDG: Case discussion and expert view/editorial input.

\section{Competing interests None.}

Provenance and peer review Not commissioned; internally peer reviewed.

\section{REFERENCES}

1 Ash-Bernal R, Wise R, Wright SM. Acquired methemoglobinemia: a retrospective series of 138 cases at 2 teaching hospitals. Medicine 2004;83:265-73.

2 FDA Drug Safety Communication: Reports of a rare, but serious and potentially fatal adverse effect with the use of over-the-counter (OTC) benzocaine gels and liquids applied to the gums or mouth. http://www.fda.gov/Drugs/DrugSafety/ucm250024. htm (accessed 15 May 2014).

3 Ayres TC, Bond JW. A chemical analysis examining the pharmacology of novel psychoactive substances freely available over the internet and their impact on public (ill)health. Legal highs or illegal highs? BMJ Open 2012;2:e000977.

4 Advisory Council on the Misuse of Drugs. Consideration of the Novel Psychoactive Substances (Legal Highs), 2011. https://www.gov.uk/government/uploads/system/ uploads/attachment_data/file/119139/acmdnps2011.pdf (accessed 15 May 2014).

5 Harvey JW, Keitt AS. Studies of the efficacy and potential hazards of methylene blue therapy in aniline-induced methaemoglobinaemia. Br J Haematol 1983;54:29-41. 